\title{
Genetic susceptibility to aspergillosis in allogeneic stem-cell transplantation
}

\author{
CRISTINA CUNHA*, FERNANDO RODRIGUES $\dagger$, TERESA ZELANTE*, FRANCO AVERSA $\ddagger$, LUIGINA ROMANI*, \\ \& AGOSTINHO CARVALHO*, $\dagger$ \\ *Microbiology Section, Department of Experimental Medicine and Biochemical Sciences, University of Perugia, Perugia, Italy, \\ †Life and Health Sciences Research Institute (ICVS), School of Health Sciences, University of Minho, Braga, Portugal, and \\ $\ddagger$ Division of Hematology and Clinical Immunology, Department of Clinical and Experimental Medicine, University of Perugia, \\ Perugia, Italy
}

Invasive aspergillosis (IA) is a major threat to positive outcomes for allogeneic stemcell transplantation (allo-SCT) patients. Despite presenting similar degrees of immunosuppression, not all individuals at-risk ultimately develop infection. Therefore, the traditional view of neutropenia as a key risk factor for aspergillosis needs to be accommodated within new conceptual advances on host immunity and its relationship to infection. Polymorphisms in innate immune genes, such as those encoding TLRs, cytokines and cytokine receptors, have recently been associated with susceptibility to IA in alloSCT recipients. This suggests that understanding host-pathogen interactions at the level of host genetic susceptibility will allow the formulation of new targeted and patienttailored antifungal therapeutics, including improved donor screening.

Keywords Aspergillosis, stem-cell transplantation, polymorphism, susceptibility, tolllike receptor, Th17

\section{Introduction}

Invasive infections by Aspergillus spp. are associated with high rates of morbidity and mortality, particularly among patients with hematological malignancies, prolonged neutropenia, treated with corticosteroids, or undergoing stem-cell or solid organ transplantation [1]. Although immunocompetent and non-atopic subjects are fairly resistant to Aspergillus infections, A. fumigatus is associated with a wide spectrum of diseases in humans, ranging from allergic syndromes to more severe forms of invasive disease [2]. These considerations imply that only in certain host-related circumstances the fungus is pathogenic or innocuous to the host [3]. As a matter of fact, the exposure to Aspergillus is ubiquitous, and there is no evidence that isolates causing invasive infection are genetically or phenotypically distinct [4].

Received 10 March 2010; Received in final revised form 28 June 2010; Accepted 13 July 2010

Correspondence: Agostinho Carvalho, Microbiology Section, Department of Experimental Medicine and Biochemical Sciences, 06126 Perugia, Italy. Tel/fax: +39(0)75 585 7498; E-mail: aacarvalho2008@gmail. com

(C) 2010 ISHAM
The most important risk factor for invasive aspergillosis (IA) has historically been neutropenia. However, it is not clear why some patients with comparable levels of apparent immunocompromise develop disease and others do not. Additionally, stem-cell transplant recipients have reduced rates of neutropenia-related infections and increased frequency of late-onset infections, concomitant with the occurrence of graft-versus-host disease (GVHD) [5]. These findings, together with the incidence of aspergillosis in non-neutropenic patients $[2,6]$, attest to the importance of specific defects in both innate and adaptive immune mechanisms in the pathogenesis of the infectious process [7-9].

Since allogeneic stem-cell transplantation (allo-SCT) dramatically impairs various layers of the immune system, subtle defects in the immune response could become clinically significant. It is important to note that in the allo-SCT setting, and depending on the hematopoietic/ nonhematopoietic compartmentalization, genetic polymorphisms may have distinct consequences regarding susceptibility to IA when present in donors or recipients. For example, it has been demonstrated that the Tlr4-mediated response to inhaled lipopolysaccharide (LPS) was solely 
dependent on hematopoietic Tlr4 expression [10]. On the contrary, in healthy individuals, the redundancy of the different immune pathways could easily camouflage such immune deficiencies. In this regard, significant advances made over the last few years into the genetic basis of IA occurring in the allo-SCT setting (Table 1) have now made clear that host genetic variants determine disparate immune responses to the fungus, ultimately contributing to different degrees of susceptibility to infection [11].

\section{The multi-faceted host immune response to Aspergillus fumigatus}

Although fungi are not mere passive bystanders in the infectious process, compelling evidence points to the mammalian immune system as the most important determinant of the host-fungus interaction. Host defense mechanisms against Aspergillus are numerous and range from relatively primitive and constitutively expressed nonspecific defenses to sophisticated adaptive mechanisms induced specifically during infection [12]. These two arms of the immune system are linked through a variety of cross-regulatory pathways, the integration of which provides for the host the complex arsenal of effector mechanisms for defense.

Among the multiple effector mechanisms of the innate immune system, resident alveolar macrophages have long been recognized as the first line of defense against Aspergillus, preventing hyphal germination and the consequent activation of inflammatory responses against the fungus [13]. In contrast, polymorphonuclear cells (PMNs) are the predominant immune cells in the acute stage of infection. PMNs may act as 'double-edged swords', as they are essential for pathogen eradication, but a disproportionate release of oxidants and proteases may also be responsible for injury to the lung [14]. This implies that tight regulatory mechanisms are required to balance protection and immunopathology for efficient control of the fungus.

The innate immune response to fungi is based on a restricted number of receptors, the pattern recognition receptors (PRRs), which play important roles in manipulating the immune response against the fungus. They improve or decrease the intensity of the inflammatory reactions often intended to sterilize the host to avoid infection. Among the signaling PRRs, the Toll-like receptor (TLR) family is undoubtedly involved in cell activation upon contact with pathogens [15], i.e., specifically, TLR2, TLR4 and TLR9 have been implicated in host defense against $A$. fumigatus [14,16-19]. It is of interest that signaling through TLR2 and TLR4 in PMNs is associated with the induction of distinct activation programs, eventually culminating in the occurrence of different patterns of fungal clearance and inflammatory pathology $[14,16]$. On the other hand, A. fumigatus is also capable of subverting the host's inflammatory response through the attenuation of TLR2- and TLR4-mediated proinflammatory responses, therefore leading to an immunosuppressive effect eventually facilitating invasiveness [20].

Table 1 Human genetic studies associating polymorphisms in immune genes and susceptibility to invasive aspergillosis in allogeneic stem-cell transplant recipients.

\begin{tabular}{|c|c|c|c|}
\hline Reference & Gene & Polymorphism/Haplotypes & Relevant findings \\
\hline Bochud et al. [29] & TLR4 & $\begin{array}{l}\text { D299G and T399I } \\
\text { (S4 haplotype) }\end{array}$ & $\begin{array}{l}\text { An association between donor S4 haplotype and risk of IA was observed, } \\
\text { especially if combined with CMV positivity ( } n=103 \text { IA cases) }\end{array}$ \\
\hline Carvalho et al. [31] & $T L R 4$ & D299G and T399I & $\begin{array}{l}\text { Donor D299G was associated with fungal colonization }(n=58) \text {, while } \\
\text { susceptibility to IA was instead decreased among pre-colonized } \\
\text { patients }(n=34)\end{array}$ \\
\hline Carvalho et al. [51] & IL23R & R381Q & Donor R381Q displayed a protective effect from IA ( $n=25$ IA cases) \\
\hline Granell et al. [59] & MBL2 & $\mathrm{O} / \mathrm{O}$ or LXA/O* & $\begin{array}{l}\text { Donor MBL-low genotype ( } 38 \% \text { vs. } 12 \%) \text { was associated with a higher } \\
\text { probability of IA ( } n=106 \text { donor-patient sibling pairs) }\end{array}$ \\
\hline Granell et al. [59] & MASP2 & D105G & $\begin{array}{l}\text { Recipient D105G ( } 67 \% \text { vs. } 14 \%) \text { was associated with a higher probability } \\
\text { of IA ( } n=106 \text { donor-patient sibling pairs) }\end{array}$ \\
\hline Kesh et al. [30] & TLR1 and TLR6 & R80T, N248S and S249P & $\begin{array}{l}\text { TLR1 R80T or combination of TLR1 N248S and TLR6 S249P from the } \\
\text { recipient were associated with IA ( } n=22 \text { IA cases })\end{array}$ \\
\hline Mezger et al. [60] & CXCL10 & $\begin{array}{l}\mathrm{C}+11101 \mathrm{~T}, \mathrm{C}+1642 \mathrm{G} \\
\quad \text { and } \mathrm{A}-1101 \mathrm{G}\end{array}$ & $\begin{array}{l}\text { Donor } C X C L 10 \text { polymorphisms were associated with IA ( } n=81 \text { IA } \\
\text { cases) }\end{array}$ \\
\hline Seo et al. [61] & IL10 & $-1082 \mathrm{~A} /-819 \mathrm{C} /-592 \mathrm{C}$ & $\begin{array}{l}\text { Recipient ACC haplotype had a protective role from IA ( } n=105 \\
\text { patients; } 9.9 \% \text { IA cases) }\end{array}$ \\
\hline Zaas et al. [57] & $P L G$ & $\mathrm{D} 472 \mathrm{~N}$ & $\begin{array}{l}\text { Risk of IA at day }>40 \text { after transplant was } 5.6 \text {-fold higher in } \mathrm{N} / \mathrm{N} \text { vs. } \\
\text { D/D recipients }(n=83 \text { IA cases })\end{array}$ \\
\hline
\end{tabular}

IA, invasive aspergillosis; CMV, cytomegalovirus; MBL, mannose-binding lectin.

*O/O and LXA/O are MBL-low haplotypes. LX represents an MBL promoter haplotype. Variants D, B and C are collectively named O, while A indicates the wild-type. 
Although the signaling pathways elicited by TLRs are known to be essential in controlling fungal infection [16], recent studies have also highlighted the pivotal role of C-type lectin receptors, in particular dectin-1, in the immune response to A. fumigatus [21]. In fact, TLRs and dectin-1, alone or synergistically, can modulate the induction of Th1- and Th17-polarizing cytokines in response to the fungus [22]. This demonstrates the involvement of innate immune receptors other than TLRs may also be required to promote adequate immune responses against A. fumigatus.

\section{TLR4 deficiency triggers paradoxical effects in invasive aspergillosis}

There is now undeniable evidence that genetic variants within recognition molecules involved in innate immunity may account, in part, for the inherited differences in human susceptibility to infection [23]. Given the broad effect of TLRs on immunity [15], their function in human disease has been investigated largely by comparing the incidence of disease among individuals with different polymorphisms in genes that participate in TLR signaling. Accordingly, the growing volume of data suggest that the ability of certain individuals to properly respond to TLR ligands may be impaired by polymorphisms in TLR genes, resulting in an altered susceptibility to, or course of, infectious or inflammatory disease [24]. Most studies so far have focused on the highly polymorphic TLR4 gene, in which two co-segregated missense polymorphisms - D299G and T399I have been described as compromising the extracellular ligand-binding domain of TLR4 [25]. These variants have been linked with blunted airway [26] and systemic inflammatory responses [27] to inhaled LPS in adults and attenuated LPS-induced responses in primary airway epithelial cells [26]. Interestingly, the D299G substitution was found to have a greater functional impact compared with the T399I genotype [26].

One of the first studies investigating the functional consequences of TLR4 polymorphisms in aspergillosis described an increased frequency of the chronic form of pulmonary aspergillosis, chronic cavitary pulmonary aspergillosis (CCPA), among D299G carriers [28]. This study, despite being relatively underpowered, has provided nevertheless interesting hypotheses regarding the involvement of TLR polymorphisms in susceptibility to fungal infections. In CCPA patients, the fungus is able to grow in pre-formed lung cavities, therefore escaping immune surveillance. Considering that subjects harboring the D299G polymorphism have an additional defect in TLR4 function, the increased susceptibility observed is likely due to an extensive impairment in fungal recognition. In addition, Tlr4-deficient mice were also found to be highly susceptible to aspergillosis, in most part due to the inability to effectively clear the fungus [14].

In the stem-cell transplantation setting, the D299G polymorphism in TLR4 was also found to increase susceptibility to IA in allo-SCT recipients from unrelated donors [29]. This genetic association was observed in both a discovery and a validation cohort, suggesting that confounding effects are unlikely and reinforcing the prognostic significance of TLR4 polymorphisms regarding IA in allo-SCT recipients. The fact that a previous study, though modest in sample size, failed to associate the same donor polymorphism with IA in allo-SCT patients [30] further stresses that the contribution of the D299G polymorphism may depend on the type of transplant and associated clinical variables. In this regard, we have recently described an association between donor D299G and colonization by A. fumigatus, but not invasive disease, in a cohort of T-cell-depleted transplant recipients from related donors [31]. Therefore, fungal colonization may not predict susceptibility to infection in the presence of D299G, at least in this particular transplant setting. The contribution of this polymorphism to colonization by A. fumigatus could be hypothesized by the fact that an abnormal TLR4 extracellular domain could be hampering its function by disrupting microbial recognition, eventually leading to fungal escape from immune surveillance (Fig. 1). However, TLR4 polymorphisms have also been shown to display a protective effect from hyper-inflammatory diseases, including atherosclerosis and related conditions [32]. Therefore, the failure to recognize the fungus may be compensated by the lack of an exuberant inflammatory response to it which may ultimately be harmful to the host. In this regard, we have found that a hyper-inflammatory state, more than the fungus itself, may contribute to susceptibility to aspergillosis and other fungal infections [33]. Thus, and although functional studies are ultimately required to confirm this possibility, by limiting the inflammatory response to the fungus, the D299G polymorphism could contribute to resistance to aspergillosis, despite evidence of fungal growth. Interestingly, the D299G polymorphism was recently shown to have a unique distribution with high prevalence in Africa and low prevalence in Europe, with the authors arguing that the benefit from reduced inflammation during malaria in Africa might have been counter-selected due to lack of inflammation in response to bacterial infections [34].

Although TLR4 has been representing the cornerstone of genetic variability to aspergillosis in the last few years, polymorphisms in other TLRs have also been linked with susceptibility to Aspergillus. In particular, a common polymorphism in the TLR9 promoter (T-1237C) has been shown to predispose to the allergic form of pulmonary aspergillosis, i.e., allergic bronchopulmonary aspergillosis (ABPA) 

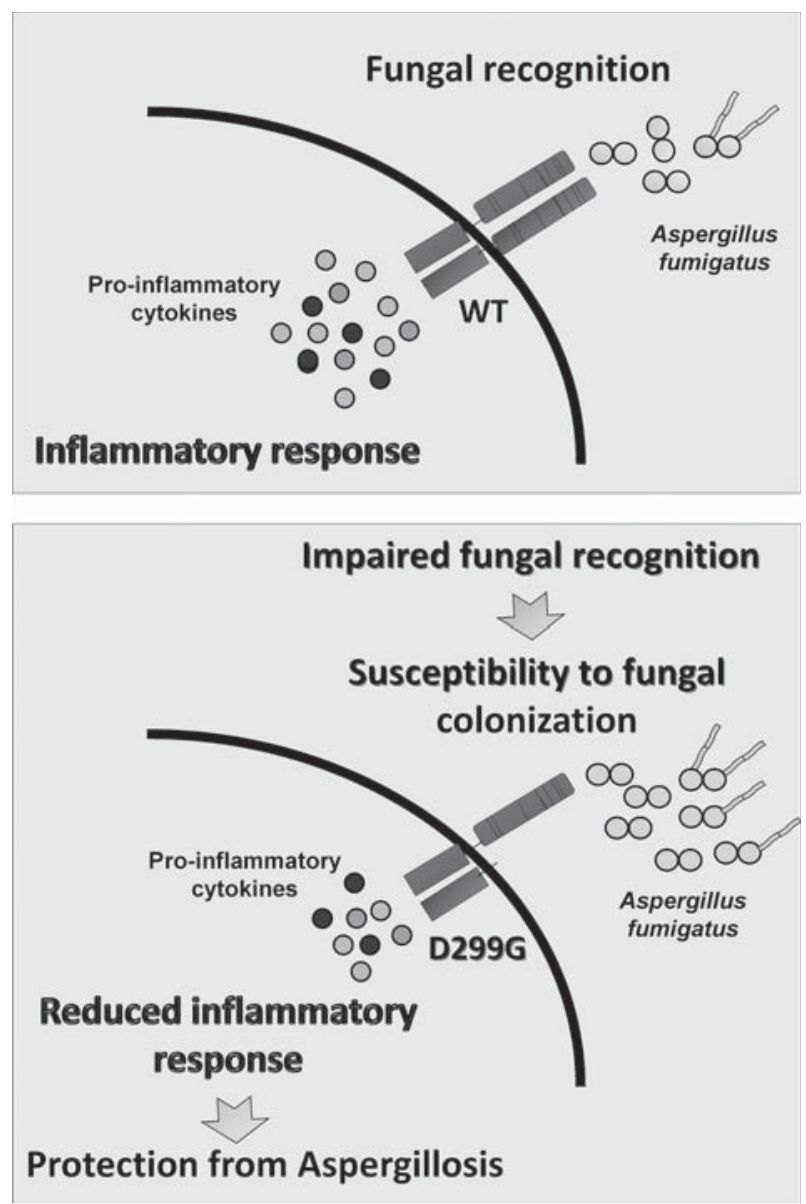

Fig. 1 The D299G polymorphism of TLR4 triggers paradoxical effects in invasive aspergillosis following stem-cell transplantation.

[28]. It is worth mentioning that we found this polymorphism to lead to an increase in TLR9 gene expression in human mononuclear cells that could be further sustained upon TLR9 engagement, presumably resulting in a gainof-function of the receptor (Rodrigues F, unpublished data). This observation is consistent with a role for TLR9 in response to allergy since Tlr9-deficient mice have been shown to be more resistant to induced allergenic stimuli [35]. In addition, PMNs from these mice had an increased capacity to kill conidia and damage Aspergillus hyphae [14]. Therefore, this argues for a detrimental role of this TLR9 polymorphism and consequent enhancement of TLR9 function in allergic aspergillosis.

\section{IL-23 and IL- I 7 have a largely detrimental role in aspergillosis}

Despite TLRs being proved to be crucial for detecting infection and activating the innate and adaptive immune systems, sustained TLR stimulation can result in chronic inflammation and is also associated with the development of certain autoimmune diseases [36]. In the last two decades, the immunopathogenesis of aspergillosis and associated inflammatory diseases has been explained primarily in terms of Th1/Th2 balance [12,37]. Until recently, CD4+ Th1 cells were considered responsible for the development of inflammatory responses to Aspergillus that were mediated by IL-12p70, the key cytokine driving Th1cell differentiation. The discovery of the IL-12 cytokinefamily member IL-23 has led to a re-evaluation of this conceptual framework [38]. IL-23, although not directly involved in Th17 differentiation, plays an important role in maintaining Th17 effector function [39]. Several experimental studies and clinical investigations confirmed that IL-23-driven Th17 cells, rather than the Th1-cell subset, mediate the inflammatory responses of autoimmune or infectious origin $[33,40]$. In addition, both IL-23 and the Th17 pathway correlate with disease severity and immunopathology in diverse infections [41,42], suggesting that IL-12 and IL-23 have distinct roles in promoting antimicrobial immune responses and diseases in vivo.

We have recently demonstrated that IL-17 has a largely detrimental role in aspergillosis in non-immunosuppressed mice, since it hampered neutrophil-mediated killing of $A$. fumigatus and the in vivo clearance of the fungus [42]. In addition, blockade of IL-23 and IL-17 greatly increased antifungal resistance, as judged by the decreased fungal growth in the relevant target organs and the ameliorated signs of inflammation, both clinically and at the tissue level [42]. Thus, despite the important role in regulating PMN homeostasis and recruitment [43], IL-23 and IL-17, by subverting the tolerogenic program of PMNs, may promote pathogen growth and infection as a result of the induced inflammatory pathology. In this regard, in a mouse model of chronic granulomatous disease, we have recently found that down-regulation of IL-23 promoted by exogenous administration of pentraxin 3 (PTX3) restored antifungal resistance and restrained the inflammatory response to the fungus through the limited expansion of IL-17-producing $\gamma \delta \mathrm{T}$-cells and the emergence of Th1/Treg responses with minimum pathology [44].

The ability of IL-17 to promote fungal germination further stresses its potential negative role in the immune responses against $A$. fumigatus [45]. Therefore, the function of the Th17 pathway may go beyond its ability to promote inflammation and subvert antimicrobial immunity by also having a direct action on fungal morphology and virulence. This may translate in concomitant Th2 cell activation, known to be strictly dependent on high levels of hyphal growth [46], and further prevent Th1 functioning. Thus, the Th17 pathway may contribute to the pathogenesis of fungal infections, occurring in a fungus-autonomous fashion at sites of infection. 
However, both positive and negative effects on immune resistance have been attributed to Th17 and IL-17 receptor (IL-17R) signaling in experimental fungal infections $[21,42,47,48]$. Thus, the role of IL-17 and Th17 cells in immunity $v s$. pathology in fungal infections and diseases remains controversial [49]. It is likely that the protective $v s$. disease-promoting effect of the IL-17/Th17 pathway may depend on the stage and site of infection, being early IL-17 able to exert some forms of antifungal resistance via defensins and neutrophils [47] while the failure to down-regulate microbe-induced expression of IL-17 could eventually be one major link connecting chronic inflammatory responses with intractable forms of fungal infection, where fungal persistence occurs in the face of an ongoing inflammation.

\section{Genetic impairment of IL-23 signaling protects from invasive aspergillosis}

Polymorphisms in cytokine genes can influence immune responses and inflammation, thereby affecting susceptibility to aspergillosis in allo-SCT recipients [50]. However, the role of polymorphisms in genes from the IL-23/Th17 inflammatory pathway in aspergillosis has only recently been addressed [51]. It has already been shown that the R381Q variant in IL23R confers protection against a number of immune-mediated diseases, such as inflammatory bowel disease [52] and psoriasis [53], but also against GVHD in recipients of hematopoietic cells from HLA-identical donors [54]. Although the genetic findings have been thoroughly replicated, much less is known about the functional consequences of this variant. A recent study demonstrated that the protective effects displayed by the R381Q polymorphism in $I L 23 R$ were due to a deficient activation of IL-23-driven Th17 responses [55]. In vitro committed effector Th17 cells derived from subjects harbouring the R381Q protective allele stimulated with IL-23 were shown to have impaired production of IL-17A compared to wild-type individuals [55]. Interestingly, IL-23 stimulation of highly purified naïve T-cells did not result in any difference whatsoever between R381Q genotypes [55], suggesting that the consequences of the polymorphism may be exclusively reflected in the function of already differentiated Th17 cells.

In T-cell-depleted allo-SCT recipients, we found that donor R381Q was associated with strong protection from IA, whereas R381Q in patients was correlated with improved overall survival [51] (Fig. 2). Strikingly, none of the patients carrying the R381Q polymorphism enrolled in the study developed aspergillosis. These findings, although requiring replication in larger independent data sets, are consistent with the protective effects of IL-23 signaling attenuation in experimental aspergillosis [42]. However, a set of polymorphisms in the ILI7A and ILI7F genes were

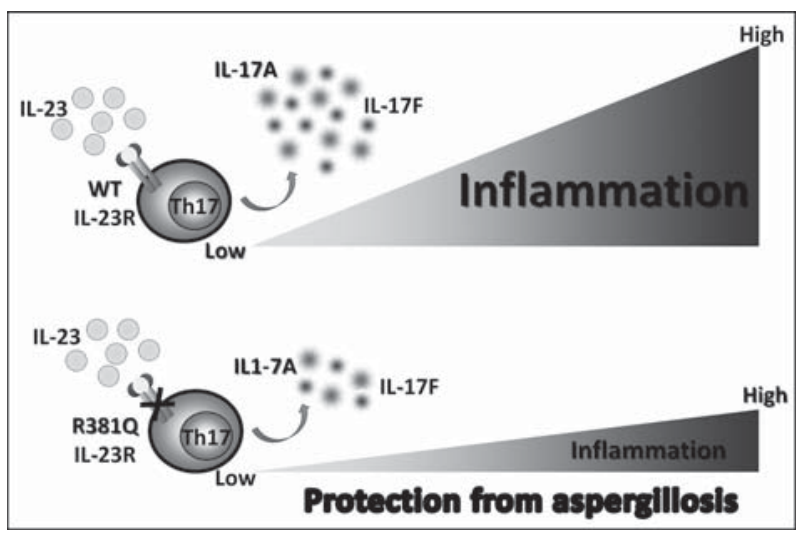

Fig. 2 The genetic impairment of IL-23 signaling promoted by the R381Q polymorphism in IL23R protects from invasive aspergillosis.

not associated with susceptibility to IA in allo-SCT recipients [51], a finding suggesting that further studies are needed to define cellular and molecular mechanisms by which protection from aspergillosis is conferred by the disruption of the IL-23/Th17 axis.

The fact that donor R381Q also increased the risk of cytomegalovirus infection [51], while being consistent with the enhancing role of IL-23 of antiviral immunity [56], indicates that Aspergillus more than viral infection may impact on survival, at least in the T-cell-depleted transplantation setting. Although the R381Q polymorphism could arguably influence survival by modifying the incidence of disease relapse or GVHD, no beneficial effects on relapse or GVHD were found [51].

\section{Immunogenetics: from bench to bedside}

Although the dissection of the genetic traits modulating susceptibility to aspergillosis is complex, the contribution of host genetics may hold the key to elucidating new risk factors for these severe, often fatal diseases. In this sense, new conceptual advances on the knowledge of host immunity need to be also accommodated from an immunogenetic point of view.

It is interesting that the genetic bases for susceptibility to human disease may also be evaluated by the screening of inbred murine strains. Recently, this approach was performed using an immunocompromised mice model of IA [57]. Through a haplotype-based computational genetic analysis of survival data, the gene encoding plasminogen $(P L G)$ was recently identified as a suitable candidate for susceptibility to Aspergillus. Consequently, a polymorphism in human PLG was reported to affect the risk of developing IA in allo-SCT recipients [57]. Besides shedding light into the role of the fibrinolytic system in the pathogenesis of IA, this approach identified a novel, biologically plausible candidate gene, validating its future 
use in the identification of less obvious disease-related genes.

Considering the key role played by many genetic polymorphisms at the host-fungus interface, further large-scale translational and clinical studies are needed to corroborate the data obtained from human cohorts. The modulation of host immune responses has been regarded as a potential therapeutic avenue with promising impact also on the treatment of fungal infections. We have recently reported that intranasal administration of a small interference RNA (siRNA) targeting the inflammatory PI3K/Akt/mTOR pathway rendered mice protection from experimental aspergillosis through attenuation of the inflammatory pathology [58]. The promising application of siRNA therapeutics, together with the awareness of the immunogenetic profile of each individual at-risk, including those subjected to allo-SCT, could prove useful to the design of fungal vaccines capable of targeting the appropriate signaling pathways and the development of therapeutics that target inflammation in aspergillosis.

In conclusion, understanding host-pathogen interactions at the level of host genetic susceptibility, together with the molecular and cellular bases affected, will allow the identification of potential therapeutic targets and the design of prophylactic strategies exerting control over the outcome of immune pathways. The genetic screening of at-risk patients may ultimately be used to individualize treatments through the formulation of new targeted and patient-tailored antifungal therapeutics, which are likely to improve the management and outcome of aspergillosis, particularly in the stem-cell transplantation setting.

\section{Acknowledgements}

We thank Cristina Massi Benedetti for digital art and editing. This work was supported by the Specific Targeted Research Projects MANASP (LSHE-CT-2006), contract number 037899 (FP6), and SYBARIS (LSHE-CT-2006), contract number 037899 (FP7), and by Italian Project PRIN 2007KLCKP8_004. Cristina Cunha and Agostinho Carvalho were financially supported by fellowships from Fundação para a Ciência e Tecnologia, Portugal (contracts SFRH/ BD/65962/2009 and SFRH/BPD/46292/2008, respectively).

Declaration of interest: The authors report no conflict of interest. The authors alone are responsible for the content and writing of the paper.

\section{References}

1 Segal BH, Walsh TJ. Current approaches to diagnosis and treatment of invasive aspergillosis. Am J Respir Crit Care Med 2006; 173: 707-717.
2 Marr KA, Patterson T, Denning D. Aspergillosis. Pathogenesis, clinical manifestations, and therapy. Infect Dis Clin North Am 2002; 16: $875-894$, vi.

3 Stergiopoulou T, Meletiadis J, Roilides E, et al. Host-dependent patterns of tissue injury in invasive pulmonary aspergillosis. Am J Clin Pathol 2007; 127: 349-355.

4 Gravelat FN, Doedt T, Chiang LY, et al. In vivo analysis of Aspergillus fumigatus developmental gene expression determined by real-time reverse transcription-PCR. Infect Immun 2008; 76: 3632-3639.

5 Garcia-Vidal C, Upton A, Kirby KA, Marr KA. Epidemiology of invasive mold infections in allogeneic stem cell transplant recipients: biological risk factors for infection according to time after transplantation. Clin Infect Dis 2008; 47: 1041-1050.

6 Denning DW, Follansbee SE, Scolaro M, et al. Pulmonary aspergillosis in the acquired immunodeficiency syndrome. $N$ Engl $\mathrm{J} \mathrm{Med}$ 1991; 324: 654-662.

7 Cenci E, Mencacci A, Fe d'Ostiani C, et al. Cytokine- and T helperdependent lung mucosal immunity in mice with invasive pulmonary aspergillosis. J Infect Dis 1998; 178: 1750-1760.

8 Roilides E, Katsifa H, Walsh TJ. Pulmonary host defences against Aspergillus fumigatus. Res Immunol 1998; 149: 454-465; discussion 523-524.

9 Romani L, Fallarino F, De Luca A, et al. Defective tryptophan catabolism underlies inflammation in mouse chronic granulomatous disease. Nature 2008; 451: 211-215.

10 Hollingsworth JW, Chen BJ, Brass DM, et al. The critical role of hematopoietic cells in lipopolysaccharide-induced airway inflammation. Am J Respir Crit Care Med 2005; 171: 806-813.

11 Carvalho A, Cunha C, Pasqualotto AC, et al. Genetic variability of innate immunity impacts human susceptibility to fungal diseases. Int J Infect Dis 2010; 14: e460-8.

12 Romani L. Immunity to fungal infections. Nat Rev Immunol 2004; 4: $1-23$.

13 Latge JP. Aspergillus fumigatus and aspergillosis. Clin Microbiol Rev 1999; 12: 310-350.

14 Bellocchio S, Moretti S, Perruccio K, et al. TLRs govern neutrophil activity in aspergillosis. J Immunol 2004; 173: 7406-7415.

15 Akira S, Uematsu S, Takeuchi O. Pathogen recognition and innate immunity. Cell 2006; 124: 783-801.

16 Bellocchio S, Montagnoli C, Bozza S, et al. The contribution of the Toll-like/IL-1 receptor superfamily to innate and adaptive immunity to fungal pathogens in vivo. J Immunol 2004; 172: 3059-3069.

17 Bretz C, Gersuk G, Knoblaugh S, et al. MyD88 signaling contributes to early pulmonary responses to Aspergillus fumigatus. Infect Immun 2008; 76: 952-958.

18 Chignard M, Balloy V, Sallenave JM, Si-Tahar M. Role of Toll-like receptors in lung innate defense against invasive aspergillosis. Distinct impact in immunocompetent and immunocompromized hosts. Clin Immunol 2007; 124: 238-243.

19 Ramirez-Ortiz ZG, Specht CA, Wang JP, et al. Toll-like receptor 9-dependent immune activation by unmethylated $\mathrm{CpG}$ motifs in Aspergillus fumigatus DNA. Infect Immun 2008; 76: 2123-2129.

20 Chai LY, Kullberg BJ, Vonk AG, et al. Modulation of Toll-like receptor 2 (TLR2) and TLR4 responses by Aspergillus fumigatus. Infect Immun 2009; 77: 2184-2192.

21 Werner JL, Metz AE, Horn D, et al. Requisite role for the dectin-1 beta-glucan receptor in pulmonary defense against Aspergillus fumigatus. J Immunol 2009; 182: 4938-4946.

22 Ferwerda G, Meyer-Wentrup F, Kullberg BJ, Netea MG, Adema GJ. Dectin-1 synergizes with TLR2 and TLR4 for cytokine production in human primary monocytes and macrophages. Cell Microbiol 2008 ; 10: 2058-2066. 
23 Garantziotis S, Hollingsworth JW, Zaas AK, Schwartz DA. The effect of toll-like receptors and toll-like receptor genetics in human disease. Annu Rev Med 2008; 59: 343-359.

24 Lasker MV, Nair SK. Intracellular TLR signaling: a structural perspective on human disease. J Immunol 2006; 177: 11-16.

25 Rallabhandi P, Bell J, Boukhvalova MS, et al. Analysis of TLR4 polymorphic variants: new insights into TLR4/MD-2/CD14 stoichiometry, structure, and signaling. J Immunol 2006; 177: 322-332.

26 Arbour NC, Lorenz E, Schutte BC, et al. TLR4 mutations are associated with endotoxin hyporesponsiveness in humans. Nat Genet 2000; 25: $187-191$.

27 Michel O, LeVan TD, Stern D, et al. Systemic responsiveness to lipopolysaccharide and polymorphisms in the toll-like receptor 4 gene in human beings. J Allergy Clin Immunol 2003; 112: 923-929.

28 Carvalho A, Pasqualotto AC, Pitzurra L, et al. Polymorphisms in toll-like receptor genes and susceptibility to pulmonary aspergillosis. J Infect Dis 2008; 197: 618-621.

29 Bochud PY, Chien JW, Marr KA, et al. Toll-like receptor 4 polymorphisms and aspergillosis in stem-cell transplantation. $N$ Engl J Med 2008; 359(17): 1766-1777.

30 Kesh S, Mensah NY, Peterlongo P, et al. TLR1 and TLR6 polymorphisms are associated with susceptibility to invasive aspergillosis after allogeneic stem cell transplantation. Ann N Y Acad Sci 2005; 1062: 95-103.

31 Carvalho A, Cunha C, Carotti A, et al. Polymorphisms in Toll-like receptor genes and susceptibility to infections in allogeneic stem cell transplantation. Exp Hematol 2009; 37: 1022-1029.

32 Kiechl S, Lorenz E, Reindl M, et al. Toll-like receptor 4 polymorphisms and atherogenesis. N Engl J Med 2002; 347: 185-192.

33 Romani L, Puccetti P. Controlling pathogenic inflammation to fungi. Expert Rev Anti Infect Ther 2007; 5: 1007-1017.

34 Ferwerda B, McCall MB, Alonso S, et al. TLR4 polymorphisms, infectious diseases, and evolutionary pressure during migration of modern humans. Proc Natl Acad Sci USA 2007; 104: 16645-16650.

35 Ramaprakash H, Ito T, Standiford TJ, Kunkel SL, Hogaboam CM. Toll-like receptor 9 modulates immune responses to Aspergillus fumigatus conidia in immunodeficient and allergic mice. Infect Immun 2009; 77: 108-119.

36 Hurst J, von Landenberg P. Toll-like receptors and autoimmunity. Autoimmun Rev 2008; 7: 204-208.

37 Romani L, Puccetti P. Protective tolerance to fungi: the role of IL-10 and tryptophan catabolism. Trends Microbiol 2006; 14: 183-189.

38 Langrish CL, Chen Y, Blumenschein WM, et al. IL-23 drives a pathogenic $\mathrm{T}$ cell population that induces autoimmune inflammation. $J$ Exp Med 2005; 201: 233-240.

39 Korn T, Bettelli E, Oukka M, Kuchroo VK. IL-17 and Th17 Cells. Апnи Rev Immunol 2009; 27: 485-517.

40 Dong C. Diversification of T-helper-cell lineages: finding the family root of IL-17-producing cells. Nat Rev Immunol 2006; 6: 329-333.

41 Happel KI, Dubin PJ, Zheng M, et al. Divergent roles of IL-23 and IL-12 in host defense against Klebsiella pneumoniae. $J$ Exp Med 2005; 202: 761-769.

42 Zelante T, De Luca A, Bonifazi P, et al. IL-23 and the Th17 pathway promote inflammation and impair antifungal immune resistance. Eur J Immunol 2007; 37: 2695-2706.

43 Smith E, Zarbock A, Stark MA, et al. IL-23 is required for neutrophil homeostasis in normal and neutrophilic mice. J Immunol 2007; 179: 8274-8279.

This paper was first published online on Early Online on 20 August 2010.
44 D'Angelo C, De Luca A, Zelante T, et al. Exogenous pentraxin 3 restores antifungal resistance and restrains inflammation in murine chronic granulomatous disease. J Immunol 2009; 183: 4609-4618.

45 Zelante T, Bozza S, De Luca A, et al. Th17 cells in the setting of Aspergillus infection and pathology. Med Mycol 2009; 47 (Suppl. 1): S162-169.

46 Mencacci A, Spaccapelo R, Del Sero G, et al. CD4+ T-helper-cell responses in mice with low-level Candida albicans infection. Infect Immun 1996; 64: 4907-4914.

47 Conti HR, Shen F, Nayyar N, et al. Th17 cells and IL-17 receptor signaling are essential for mucosal host defense against oral candidiasis. J Exp Med 2009; 206: 299-311.

48 Huang W, Na L, Fidel PL, Schwarzenberger P. Requirement of interleukin-17A for systemic anti-Candida albicans host defense in mice. J Infect Dis 2004; 190: 624-631.

49 Zelante T, De Luca A, D’Angelo C, Moretti S, Romani L. IL-17/Th17 in anti-fungal immunity: what's new? Eur J Immunol 2009; 39: 645-648.

50 Weissinger EM, Dickinson AM. Immunogenomics and proteomics in hematopoietic stem cell transplantation: predicting post-hematopoietic stem cell transplant complications. Cancer Treat Res 2009; 144: 1-35.

51 Carvalho A, Cunha C, Di Ianni M, et al. Prognostic significance of genetic variants in the IL-23/Th17 pathway for the outcome of T cell-depleted allogeneic stem cell transplantation. Bone Marrow Transplant. Advance online publication 22 February 2010; doi: 10.1038/bmt.2010.28.

52 Duerr RH, Taylor KD, Brant SR, et al. A genome-wide association study identifies IL23R as an inflammatory bowel disease gene. Science 2006; 314: 1461-1463.

53 Cargill M, Schrodi SJ, Chang M, et al. A large-scale genetic association study confirms IL12B and leads to the identification of IL23R as psoriasis-risk genes. Am J Hum Genet 2007; 80: 273-290.

54 Elmaagacli AH, Koldehoff M, Landt O, Beelen DW. Relation of an interleukin-23 receptor gene polymorphism to graft-versus-host disease after hematopoietic-cell transplantation. Bone Marrow Transplant 2008; 41: 821-826.

55 Meglio PD, Cesare AD, Laggner U, et al. F.15. A gene-to-function analysis of IL-23R Arg381Gln polymorphism reveals impaired IL-17A production in Th17 Cells. Clin Immunol 2009; 131(Suppl. 1): S97.

56 Kohyama S, Ohno S, Isoda A, et al. IL-23 enhances host defense against vaccinia virus infection via a mechanism partly involving IL-17. J Immunol 2007; 179: 3917-3925.

57 Zaas AK, Liao G, Chien JW, et al. Plasminogen alleles influence susceptibility to invasive aspergillosis. PLoS Genet 2008; 4: e1000101.

58 Bonifazi P, D'Angelo C, Zagarella S, et al. Intranasally delivered siRNA targeting PI3K/Akt/mTOR inflammatory pathways protects from aspergillosis. Mucosal Immunol 2010; 3: 193-205.

59 Granell M, Urbano-Ispizua A, Suarez B, et al. Mannan-binding lectin pathway deficiencies and invasive fungal infections following allogeneic stem cell transplantation. Exp Hematol 2006; 34: 1435-1441.

60 Mezger M, Steffens M, Beyer M, et al. Polymorphisms in the chemokine (C-X-C motif) ligand 10 are associated with invasive aspergillosis after allogeneic stem-cell transplantation and influence CXCL10 expression in monocyte-derived dendritic cells. Blood 2008; 111: 534-536.

61 Seo KW, Kim DH, Sohn SK, et al. Protective role of interleukin-10 promoter gene polymorphism in the pathogenesis of invasive pulmonary aspergillosis after allogeneic stem cell transplantation. Bone Marrow Transplant 2005; 36: 1089-1095. 